\title{
Diálogos entre Colonialidade e Gênero
}

\author{
Jéssica Antunes Ferrara' (iD) 0000-0003-4763-8936 \\ 'Universidade Federal de Juiz de Fora, São Pedro, MG, Brasil. \\ 36036-900-ppg.letras@ufjf.edu.br
}

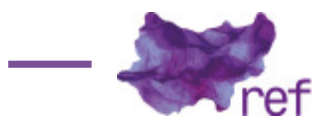

Resumo: No presente estudo tem-se por objetivo apresentar as proposições de Frantz Fanon acerca das consequências do colonialismo na formação psíquica e cultural do sujeito colonizado e articulálas à condição específica da mulher dentro desse contexto. Tenciona-se discutir a herança do colonialismo na vida dessas mulheres, nas sociedades em que vivem e nos projetos de descolonização cultural. Para tanto, serão admitidas as observações e argumentos do psicanalista e filósofo martiniquense presentes em suas duas principais obras, Pele Negra, Máscaras Brancas (1952) e Os Condenados da Terra (1961). Apesar de ambas as obras não tratarem sobre a questão da mulher de forma aprofundada, elas oferecem mecanismos de análise que possibilitam a intersecção das formas de dominação e a melhor apreensão dos problemas socioculturais no cenário da descolonização. Palavras-chave: Frantz Fanon; colonialismo; feminismo; interseccionalidade

Dialogues Between Coloniality and Gender

Abstract: This study aims to present Frantz Fanon's propositions concerning the consequences of colonialism on the psychic and cultural formation of the colonized individual. The study also aims to articulate these consequences to the specific condition of women. It will import the legacy left by colonialism in the lives of these women and the colonial impact on the societies in which these women live. In addition, it is necessary to think about the projects of cultural decolonization. The main works of Fanon will be used for this study: Black Skin, White Masks (1952) and The Wretched of the Earth (1961). Although both works do not discuss the issue of women in depth, the works offer analysis mechanisms that make it possible to understand the intersection of oppression and allow a better apprehension of sociocultural problems in the context of decolonization.

Keywords: Frantz Fanon; Colonialism; Feminism; Intersectionality

\section{Frantz Fanon em uma leitura feminista interseccional}

A partir de uma concepção interseccionalista de análise social, pretende-se, ao longo deste artigo, apresentar uma leitura das obras Pele Negra, Máscaras Brancas (2008) e Os Condenados da Terra (1968), de Frantz FANON (1968; 2008), articulando-as a concepções feministas, principalmente aquelas propostas por teorias que se ocupam em entrelaçar distintas formas de diferenças e desigualdades sociais. Apesar da emergência do debate interseccional no feminismo ser datada, na maioria das pesquisas, no final da década de 1990, de acordo com Avtar BRAH e Ann PHOENIX (2004, p. 77), esse pensamento de associação dos múltiplos mecanismos de produção de desigualdade ocorre desde o surgimento dos movimentos feministas abolicionistas dos Estados Unidos, ainda no século XIX. Na América Latina foi o feminismo descolonial, propulsionado principalmente por mulheres negras, indígenas e lésbicas, que surgiu como elemento base à análise crítica das muitas facetas que a dominação pode assumir - especificamente dentro desse espaço geopolítico -, tais como a dependência capitalista que os países territorialmente descolonizados possuem em relação aos grandes centros, a racialização, a sexualização e a heteronormativização das relações sociais, dentre outras (Ochy CURIEL, 2010, p. 70).

Todas essas articulações revelam o quanto as relações de poder e os mecanismos de opressão são diversos e atingem a sociedade de maneira distinta de acordo com suas 
categorizações e formas históricas de reprodução. Intenta-se aqui, pois, demonstrar uma conexão entre teorias que evidenciamos sintomas do colonialismo nas sociedades atuais e teorias que apresentam reflexões sobre os mesmos traços associados aos sinais da histórica dominação masculina. Essa conexão é possibilitada justamente através da interseccionalidade, que é, em uma explicação breve,

a forma como, na constituição da subjetividade e da identidade dos sujeitos, diversas categorias como raça, classe, gênero, religião, idade, orientação sexual, etc., se cruzam produzindo formas particulares de opressão ou privilégio. A interseção é responsável pela formação de um sujeito específico e, consequentemente, de determinados lugares sociais, de formas de ser e estar no mundo e relações interpessoais (Vanilda Maria de OLIVEIRA, 2006, p. 66).

Com base na análise interseccional, portanto, pode-se associar a categoria de opressão gerada pelo colonialismo à gerada pela dominação masculina, situando a mulher colonizada em uma condição de dupla opressão. No Brasil, por exemplo, "a mulher sempre foi relegada ao serviço do homem, ao silêncio, à dupla escravidão, prostituição ou a objeto sexual" (Thomas BONNICl, 2009, p. 266), denotando uma herança colonial que associa a hiperssexualização do corpo feminino à subjugação de sua nacionalidade. Torna-se evidente, então, o fato de o colonialismo e o próprio discurso colonialista trazerem juntos de si as perspectivas patriarcalistas e sexistas já difundidas e vivenciadas na Europa, que têm como um dos pilares ideias de filósofos como Rousseau e Hegel, fomentadores da reflexão do humano e da organização social no mundo ocidental. Como lembra Herbert MARCUSE (1972, p. 110), essas ideologias procuravam naturalizar a posição superior do homem e universalizar tudo que se referia ao masculino enquanto inferiorizavam e enclausuravam a mulher em suas subjetividades. Porém, essa opressão do feminino adquire desdobramentos muito mais profundos quando relacionadas ao racismo.

É nesse ponto que os textos de Fanon convergem com os pressupostos feministas, posto que tanto uns, quanto os outros, situam em um processo histórico as relações de poder entendidas como naturais, mostrando que se tratam de consequências de um sistema estrutural complexo da sociedade. Ambos procuram evidenciar "os processos que são responsáveis pela transformação da história em natureza, do arbitrário cultural em natural" (Pierre BOURDIEU, 2002, p. 8), a fim de desenvolverem a alteridade de uma maneira desconhecida até então, impedida pelos essencialismos impostos pelos grupos hegemônicos.

Aqui se faz importante trazer à discussão a noção de essencialismo estratégico, dada pela teórica Gayatri Chakravorty SPIVAK (2010). Ela afirma que os grupos sociais considerados em uma posição subalterna, dos quais fazem parte mulheres, negros, indígenas, colonizados etc., são comumente reduzidos a um tipo de essência que os simplificam e os estereotipam, negando assim suas variadas experiências e formas de estar no mundo. Além disso, essa essencialização naturaliza os efeitos de dominação, tornando problemático o uso das categorias no momento de uma análise social. A autora sugere, então, que seja feito um uso estratégico dessas categorias essencializadoras, julgando serem elas necessárias para a formação da identificação do sujeito, com vistas à realização de uma mobilização política. Nessa perspectiva, Diana Marcela Gomez CORREAL (201 1 , p. 58) postula que há a necessidade de se ir além do simples reconhecimento das diferenças, observado comumente no relativismo e no multiculturalismo, para que se problematize a suposta essencialidade da mulher sem perder de vista a potência política que carrega seu reconhecimento enquanto sujeito coletivo. Logo, serão utilizadas ao longo do trabalho as categorias 'mulheres', 'colonizados', 'negros' etc., a fim de construir uma unidade dentro da diferença visando a um ponto de entendimento que permita a identificação. Essa estratégia é uma contribuição da reflexão feminista pós-estruturalista ao feminismo contemporâneo (Luis Felipe MIGUEL, 2004, p. 54), mas que também foi utilizada por Frantz Fanon ao falar diretamente aos negros ainda na década de 1950 na obra Pele Negra, Máscaras Brancas e, mais tarde, em Os Condenados da Terra.

\section{O inconsciente coletivo}

Em sua primeira obra, Pele Negra, Máscaras Brancas, Fanon (2008) discorre sobre o racismo e alega não existirem categorias sociais mais racistas do que as outras; ou se é racista, ou não se é racista (FANON, 2008, p. 85). Essa afirmação leva ao raciocínio de que o racismo, independente da classe em que se mostre mais evidente, é algo que atinge uma nação por inteira, porque é sintoma da construção estrutural daquele local, de um sistema muito mais profundo e complexo. Compreende-se, assim, que o racismo é o elemento cultural "mais visível, mais quotidiano, para dizermos tudo, em certos momentos, mais grosseiro de uma estrutura dada" (FANON, 1980, p. 35). No prefácio que escreveu para Os Condenados da Terra, Jean-Paul SARTRE (In FANON, 1968, p. 9) lembra que quando analisou o antissemitismo na Europa já havia atentado aos leitores sobre a discriminação como algo estrutural daquela sociedade. Fanon levou essa concepção para o campo psicológico e para o contexto dos países coloniais, e, aqui, pode-se ir mais adiante e levar para a vivência das mulheres naturais desses países. Com colonialismo, racismo e patriarcalismo 
andando de mãos dadas, evidenciam-se as ideologias tomadas como mecanismo de submissão e dominação. Essa convergência se contextualiza na própria fala de Fanon (2008), que reconhece que "é utópico procurar saber em que um comportamento desumano se diferencia de outro comportamento desumano" (p. 85), tornando clara a máxima de que não existe libertação social enquanto um só grupo ainda se encontrar oprimido.

A relação de poder dada entre colonizador e colonizado é investigada de maneira profunda por Fanon. A estrutura preconceituosa da Europa, que se expandirá mais tarde devido à imposição de sua ideologia nos países colonizados, ocorre porque o inconsciente coletivo europeu é baseado em um complexo de autoridade, isto é, em uma ideia de ser humano superior, perpetuada ao longo dos séculos através de materiais simbólicos, tais como mitos e lendas. Esse complexo gera no outro, no povo que sofre a aniquilação de sua própria cultura, um complexo de inferioridade (FANON, 2008, p. 34). É o começo de um trabalho epistemológico de relações baseadas naquilo que Bourdieu (2002) chama de violência simbólica, ${ }^{1}$ que é

invisível [a] suas próprias vítimas, que se exerce essencialmente pelas vias puramente simbólicas da comunicação e do conhecimento, ou, mais precisamente, do desconhecimento, do reconhecimento ou, em última instância, do sentimento. Essa relação social extraordinariamente ordinária oferece também uma ocasião única de apreender a lógica da dominação, exercida em nome de um princípio simbólico conhecido e reconhecido tanto pelo dominante quanto pelo dominado, de uma língua (ou uma maneira de falar), de um estilo de vida (ou uma maneira de pensar, de falar ou de agir) e, mais geralmente, de uma propriedade distintiva, emblema ou estigma, dos quais o mais eficiente simbolicamente é essa propriedade corporal inteiramente arbitrária e não predicativa que é a cor da pele (p. 7-8).

O fato de a história da civilização estar sempre reafirmando o caráter heroico do homem branco através das narrativas épicas, por exemplo, fez com que o homem e a mulher não ocidentais fossem colocados como inferiores por não corresponderem aos símbolos ocidentais, ao ideário civilizatório. Nesse movimento entram diversos fatores, inclusive o linguístico, em que o sujeito também se forma através de um real, que é simbólico, representado pelo uso da linguagem, pelas escolhas linguísticas, ou até por símbolos anteriores à linguagem (Jacques LACAN, 1999, p. 12). Por repetição, reafirmação constante, a cultura ocidental se tornou sinônimo de cultura, as narrativas épicas tornaram-se sinônimo de literatura, o homem branco se tornou sinônimo de humanidade. Para além disso, no ensaio Racismo e cultura (p. 35), Fanon (1980) aponta que todo o desenvolvimento técnico trazido pelo grupo colonizador atuou enquanto elemento básico de autorização para o empreendimento dessa dominação organizada. Criou-se, pois, um inconsciente coletivo, que não é um simples impulso ou instinto que guia cegamente uma sociedade, e sim algo vivo dentro dela, muito bem estruturado historicamente, fazendo com que o sujeito seja alienado em relação à sua humanidade.

Quando o homem branco ocidental, que já traz consigo um conflito de diferenciações dentro de sua própria cultura (homem/mulher, heterossexual/homossexual, adulto/criança etc.), se defronta com não brancos e não ocidentais, o olhar é projetado com certa fobia porque seu inconsciente coletivo é o da superioridade, da universalidade. Assim, ele lega ao outro o mesmo estado de inferioridade que lega aos diferentes de sua própria cultura. Para citar um exemplo, Tzvetan TODOROV (1983), em A Conquista da América, relata a dificuldade que Colombo encontrou em compreender os índios como humanos, semelhantes, sem os identificar com pássaros e paisagens ou sem animalizar seus costumes. Ao tratar de índias mulheres a situação piora. Na cultura de Colombo, isto é, na cultura europeia, o par de alteridade homem/mulher já possuía uma relação problemática de opressão, erigida historicamente e que passa pelo atributo mais constituinte da personalidade do descobridor em questão, a religiosidade. Soma-se, então, essa categoria inferiorizada na cultura ocidental, que é a mulher, à inferiorização do indígena - e, mais tarde, do negro. Os olhos do colonizador para as mulheres indígenas e negras são de dupla inferiorização. Nas palavras de Todorov (1983), "ser índio, e ainda por cima mulher, significa ser posto, automaticamente, no mesmo nível que o gado" (p. 46). Ele ainda fala sobre a dupla colonização da índia, figura que fora exposta não só a trabalhos braçais, mas também a violências sexuais: "as mulheres índias são mulheres, ou índios ao quadrado; nesse sentido, tornam-se objeto de um duplo violentar" (TODOROV, 1983, p. 46).

Fanon então define o que acredita ser o inconsciente coletivo numa diferenciação que faz da expressão quando utilizada por Jung, que entende ser o inconsciente coletivo uma "substância cerebral herdada. Mas o inconsciente coletivo, sem que haja necessidade de recorrer aos genes, é simplesmente o conjunto dos preconceitos, mitos, atitudes coletivas de um grupo determinado" (FANON, 2008, p. 159). Em resumo, Fanon privilegia os aspectos culturais da coletividade, em detrimento dos arquétipos atemporais que ocupam centralidade na teoria de Jung.

' O conceito de violência simbólica começa a ser utilizado por Bourdieu na obra La Reproduction. Éléments pour une théorie du système d'enseignement (1970), dezoito anos após a publicação original de Pele Negra, Máscaras Brancas (1952), fato que declara o horizonte de questionamentos epistemológicos que tange este trabalho. 
O resultado disso tudo é uma questão de identificação. A partir da leitura dos textos de Fanon, conclui-se que a construção do indivíduo é dependente da identificação que ele faz das representações sociais com sua própria imagem. Essas representações, permeadas por um inconsciente coletivo dado e adquirido culturalmente, é que gerarão as relações de poder. A diferenciação, portanto, também é parte da construção do sujeito, moldando o ego. O problema surge no contexto do colonizado porque os mecanismos referenciais não o reconhecem, o ambiente colonial simplesmente não o enxerga e, se o faz, o inferioriza, criando estereótipos. Dessa maneira, o chamado

'complexo de inferioridade' do colonizado começa [...] na infância, uma vez que há uma divergência profunda entre o universo infantil das referências familiares e o universo público, marcado pela dominação e tutela europeia. Para uma criança europeia, que sai do ambiente doméstico para o público, há uma coerência entre as figuras do universo familiar (alicerces da psique) e os símbolos coletivos e nacionais. As referências coletivas, para o branco, falam sobre sua família, seus pais e sobre ele próprio. O mesmo não ocorre com o colonizado (Thiago SAPEDE, 2011, p. 47).

Ainda em Pele Negra, Máscaras Brancas, Fanon (2008) discute que uma das formas adquiridas por essa não identificação é a recusa de um vínculo íntimo entre negros, posto que estes passam a desejar a branquitude sistematicamente imposta enquanto cultura hegemônica. Qualquer contato com o branco passa a ser preferível porque o negro começa a ser em si e por si malvisto. Há, a partir da construção desse inconsciente coletivo que culmina em um complexo de inferioridade, a assimilação dos valores culturais brancos e europeus, e, consequentemente, a negação da negritude (FANON, 2008, p. 34). Dentro dessa perspectiva, o autor martiniquense elabora uma crítica psicanalítica do romance autobiográfico de Mayotte CAPÉCIA (1948), intitulado Je suis Martiniquaise, na qual acredita que a escritora falha ao expor sua rejeição à sua própria raça. Na obra, Capécia discorre sobre seu casamento com um homem branco chamado André, de quem "aceita tudo. Ele é o seu senhor. Dele ela não reclama nada, não exige nada, senão um pouco de brancura na vida" (FANON, 2008, p. 54). Para Fanon, esse texto seria um desserviço para a descolonização do pensamento e dos costumes das mulheres martiniquenses que acreditavam na necessidade de embranquecer a nação. Em suas palavras, elas desejavam "embranquecer a raça, salvar a raça, mas não no sentido que poderíamos supor: não para preservar "a originalidade da porção do mundo onde elas cresceram', mas para assegurar sua brancura" (FANON, 2008, p. 57).

A crítica de Fanon ao texto de Capécia gerou discussões em torno de um suposto tom misógino utilizado pelo autor ao se referir tão duramente à obra em questão. Contudo, o filósofo Lewis R. GORDON (2015, p. 46), em What Fanon Said, argumenta que não há intenção sexista na fala de Fanon, posto que ele apenas traz ao centro do debate o entrelaçamento do elemento racial e de gênero na construção do desejo da subjetividade colonizada. Aproximando as postulações de Simone de BEAUVOIR (2009) em O Segundo Sexo às expostas em Pele Negra, Máscaras Brancas, Gordon (2015) afirma que em ambas as obras os autores acreditam que as condições sociais impostas por uma inferioridade criada e manipulada pelo dominador impede o desenvolvimento humano. Destarte, o desejo, parte crucial desse processo, subverte-se em Capécia e adquire características problemáticas, culminando em uma alienação psíquica da mulher negra que não se aceita e tenta, através do exercício de sua sexualidade, embranquecer-se de corpo e de pensamento (FANON, 2008, p. 56).

Desta forma, Fanon procura demonstrar que é o sistema arbitrário, a hegemonia do homem branco ocidental e seu complexo de superioridade que criam o inferior. É o opressor que cria o inferiorizado (FANON, 2008, p. 90). Dentro desse raciocínio, a inferiorização da mulher colonizada passa por dois níveis: o anterior à colonização, que é a realocação do patriarcalismo, e o da mentalidade colonialista, subjugadora de povos (BONNICI, 2009, p. 267). Entretanto, essa permutação do local patriarcal cria uma nova lógica de submissão para as mulheres não ocidentais que se difere da realidade das mulheres brancas europeias, fato que torna a situação muito mais complexa do que parece a priori. O inconsciente coletivo europeu, ao ser passado ao contexto colonial, criou a mesma relação de poder homem/mulher existente no Ocidente. Isto significa que os próprios colonizados verão surgir em si mesmos a submissão da mulher perante o homem; porém, não só perante o homem europeu, mas também o homem igualmente subjugado, o homem colonizado. Como lembra Fanon (2008, p. 162), é através do inconsciente coletivo que o colonizado adota como seus todos os arquétipos do colonizador. Soma-se a isso o fato de que o europeu não incluía o colonizado nas categorizações do humano. Para ele, aquilo que não é europeu, é, no inconsciente de sua coletividade, qualquer outra coisa, seja objeto ou animal, o que piora cada vez mais a condição da mulher nesses contextos. A condição da mulher negra durante a escravatura elucida essas afirmações: 
Os comportamentos dos donos de escravos para as mulheres escravas eram: quando era rentável explorá-las como se fossem homens, sendo observadas, com efeito, sem distinção de gênero, assim o faziam, mas quando elas podiam ser exploradas, castigadas e reprimidas em formas ajustadas apenas às mulheres, elas eram fechadas dentro do seu papel exclusivo de mulheres (Angela DAVIS, 2013, p. 11).

As práticas do colonialismo foram internalizadas na sociedade que emergia, podendo ser percebidas sob alguns rastros até nos dias de hoje, como por exemplo a insistente hiperssexualização dos corpos negros, fato citado tanto por Fanon quanto por Davis. Diante de uma análise dessa internalização de práticas, a teórica feminista Maria LUGONES (2014), ao abordar precisamente o modo como foi passado ao colonizado a ideologia do colonizador, explica que há,

começando com a colonização das Américas e do Caribe, uma distinção dicotômica, hierárquica entre humano e não humano e que foi imposta sobre os/as colonizados/as a serviço do homem ocidental. Ela veio acompanhada por outras distinções hierárquicas dicotômicas, incluindo aquela entre homens e mulheres. Essa distinção tornou-se a marca do humano e a marca da civilização. Só os civilizados são homens ou mulheres. Os povos indígenas das Américas e os/as africanos/as escravizados/as eram classificados/as como espécies não humanas - como animais, incontrolavelmente sexuais e selvagens. O homem europeu, burguês, colonial moderno tornou-se um sujeito/agente, apto a decidir, para a vida pública e o governo, um ser de civilização, heterossexual, cristão, um ser de mente e razão. A mulher europeia burguesa não era entendida como seu complemento, mas como alguém que reproduzia raça e capital por meio de sua pureza sexual, sua passividade, e por estar atada ao lar a serviço do homem branco europeu burguês (p. 936).

Lugones (2014, p. 938) problematiza a questão de gênero nos contextos coloniais porque acredita que, apesar de os colonizadores usarem essa dicotomia hierárquica que é homem/ mulher no momento do exercício de uma suposta "missão civilizatória", nunca foi intenção incluir os colonizados nas categorias humanas. Dessa forma, a dicotomização de gênero não foi incluída na sociedade colonial a partir de uma identificação, isto é, não foram construídas identidades, ainda que compulsórias - posto que se entende o gênero como construção social arbitrária. Na verdade, foi apenas uma parte sistêmica do intuito civilizatório, que tinha como normatividade a conexão entre gênero e civilização, apoiada no cristianismo. Logo, existiu - e, com o imperialismo, ${ }^{2}$ ainda existe - uma colonização de gênero nesses espaços outrora subjugados. E aqui Fanon e as teorias feministas se encontram mais uma vez; todo o arcabouço de práticas discriminatórias foi introduzido e, mais tarde, reproduzido nas sociedades pós-coloniais através de um mecanismo impossível de ser contestado: a violência.

\section{O argumento da violência}

Em Os Condenados da Terra, Fanon (1968) aborda a violência como elemento penetrante no inconsciente coletivo dos povos oprimidos. De acordo com ele, nas sociedades capitalistas, a submissão é uma condição constituída a partir de mentores morais, passada de gerações em gerações através do ensino religioso ou até mesmo leigo. Já nos países coloniais, a inferioridade é imposta por meio da violência, exercida pelos militares em sua maioria, mostrando que

o intermediário do poder utiliza uma linguagem de pura violência. O intermediário não torna mais leve a opressão, não dissimula a dominação. Exibe-as, manifesta-as com a boa consciência das forças da ordem. O intermediário leva a violência à casa e ao cérebro do colonizado (FANON, 1968, p. 28).

Para situar as mulheres nessa questão, é fundamental dizer que nas sociedades capitalistas a mulher é subjugada à passividade econômica, social e sexual das mais diversas formas, que podem ser desde o ensino religioso, como comenta Fanon, até práticas leigas, como a divisão sexual do trabalho, a separação das esferas pública e privada, a representatividade política - ou mais especificamente a falta de. Nota-se que não é intuito dizer que em países desenvolvidos economicamente não exista violência contra a mulher. Aqui, a intenção é explorar as formas pelas quais a categoria de inferiorizada foi criada na mulher em contextos colonizados. Isto posto, Lugones (2014) conta que

a 'missão civilizatória' colonial era a máscara eufemística do acesso brutal aos corpos das pessoas através de uma exploração inimaginável, violação sexual, controle da reprodução e terror sistemático (por exemplo, alimentando cachorros com pessoas vivas e fazendo algibeiras e chapéus das vaginas de mulheres indígenas brutalmente assassinadas) (p. 938).

\footnotetext{
${ }^{2}$ Utilizo-me do termo 'imperialismo' dentro da perspectiva de Edward W. Said, quando se refere a práticas que um local dominante exerce governando um território distante (SAID, Edward W. Cultura e Imperialismo. Tradução de Denise Bottmann. São Paulo: Companhia das Letras, 1995. p. 40).
} 
É de acordo com essas práticas que a violência foi penetrando o inconsciente coletivo do grupo colonizado. Essa construção estrutural do inconsciente a partir de uma forma de linguagem simbólica, ou seja, de um real que é simbólico, é uma ideia de Lacan que Fanon revisita. Ademais, percebe-se que quanto mais autoritária e arbitrária é a base do opressor, o oprimido se vê mais inibido, tornando os meios de opressão mais fáceis de serem executados - principalmente através dos complexos criados: o da superioridade ou autoridade e o da inferioridade. Fanon (1968, p. 39) ainda comenta sobre o extremo confinamento do ser oprimido, que é lembrado, através da violência, o tempo todo a se manter recluso em seu lugar, nunca ultrapassando os limites impostos pelo opressor. Essa contenção gera uma repressão energética muscular muito forte, que acaba explodindo entre os próprios grupos subjugados, gerando brigas e disputas entre os mesmos. $O$ sistema colonial faz com que o colonizado viva sob um estado de tensão constante.

A violência não apenas física, mas simbólica, é também uma eficaz forma de fazer penetrar a inferiorização na psique do colonizado (FANON, 1968, p. 31). Ela é dada mediante a diminuição, ridicularização, demonização da cultura dominada. É uma maneira de desumanizar o colonizado, de animalizá-lo, pervertendo os valores do povo, como se eles fossem depravados ou inexistentes só por serem diferentes. O colonizador nega a existência de seus valores no colonizado, acreditando serem os seus os únicos valores do mundo e assim caracterizando o Outro como o mal em absoluto a partir da criação de estereótipos. No primeiro capítulo da obra Sociología de una Revolución (p. 19-45), Fanon (1976) comenta acerca da utilização do véu por parte das mulheres argelinas. Sabendo-se que a vestimenta faz parte das características mais evidentes de uma sociedade, desacreditá-la, ridicularizá-la e até mesmo proibi-la não é nada mais do que um ato violento contra determinada cultura. A antipatia da cultura ocidental pelo véu simboliza seu imaginário colonizador. Não é colocado em dúvida o aspecto patriarcal da sociedade argelina, porém, o que Fanon procura destacar é o elemento colonizador que vem atrelado à necessidade do europeu em desapropriar a mulher de uma indumentária própria de sua cultura. $\mathrm{O}$ corpo da mulher, nesse sentido, torna-se um campo de batalha em que a cada véu que abandona, reitera a vulnerabilidade cultural à qual sua nação fora exposta. Por conseguinte, percebe-se que em ambientes colonizados é de maneira mais profunda que se dá a depravação da mulher, de seu corpo não europeu, de tudo que caracteriza o feminino nesse contexto, a nível social e psicológico.

Indo além em sua análise dos efeitos da colonização, o autor postula que toda a repressão energética que essa violência, seja literal ou simbólica, causa no colonizado, gera grandes explosões visando à vazão dessa energia. Por conseguinte,

a dança, a sexualidade e a possessão, os esportes, entre outros, tornam-se veículos fundamentais de liberação energética. A violência, porém, torna-se para Fanon a via por excelência de descarga energética. Essas explosões de violência se darão sobretudo longe da vigilância dos colonos, ou seja, entre os próprios colonizados. Esse fenômeno é chamado pelo autor de 'autodestruição' do colonizado, que causará violência endêmica nos bairros periféricos (SAPEDE, 2011 , p. 51).

Em vista disso, os colonizados acabam por reafirmar os estereótipos criados pelos colonos porque se tornam extremamente corporais e instintivos, alimentando o sistema e o imaginário racista que permeiam toda a sociedade. A lógica colonialista é a de implementação de práticas e ideologias que mantêm o colonizado na posição de inferiorizado, o que cria um cenário esquizofrênico. A suposta inércia que é apontada nos povos subjugados é apenas um resultado óbvio desse processo, já que há certa impossibilidade de o sujeito evoluir "de modo diferente que não no quadro de uma cultura que o reconhece e que ele decide assumir" (FANON, 1980, p. 38). O europeu, nesse contexto, aponta como se deve agir, porque é aparentemente dessa forma que ele detém o poder. E essa violência como arma de controle e sinônimo de autoridade é internalizada e repetida pelos oprimidos até quando eles próprios são as vítimas. É o que Bourdieu (2002) diz sobre a violência simbólica contida na dicotomia de gênero homem/mulher:

[...] a representação androcêntrica da reprodução biológica e da reprodução social se vê investida da objetividade do senso comum, visto como senso prático, dóxico, sobre o sentido das práticas. E as próprias mulheres aplicam a toda a realidade e, particularmente, às relações de poder que se veem envolvidas em esquemas de pensamento que são produto da incorporação dessas relações de poder e que se expressam nas oposições fundantes da ordem simbólica. Por conseguinte, seus atos de conhecimento são, exatamente por isso, atos de reconhecimento prático, de adesão dóxica, crença que não tem que se pensar e se afirmar como tal e que 'faz', de certo modo, a violência simbólica que ela sofre (p. 45).

Essa reprodução do inconsciente coletivo violento, dicotômico, discriminatório e excludente, que aparece não só nas relações de poder já existentes no patriarcado europeu, como também no colonialismo, perdurará mesmo após a libertação territorial dos países. A libertação cultural é de difícil execução porque os povos sofreram processos de dominação violentos em relação a seus costumes e crenças. Segundo Fanon (1968, p. 197-198), o colonizador desarticulou 
violentamente o modo de viver do colonizado, massacrando sua cultura das mais diversas formas, tais como negando uma realidade nacional, escravizando homens e mulheres, empurrando os povos autóctones para a periferia, construindo novas relações jurídicas etc. Foram esforços para que o colonizado se admitisse inferior, percebesse sua cultura como fruto do puro instinto, não enxergasse sua comunidade como uma nação e até mesmo pensasse que sua própria estrutura biológica fosse subalterna. Em outras palavras,

os sistemas de coerção ideológica se faziam tanto mais pela introjeção no povo e nas elites da sociedade subjugada de uma visão de mundo e de si mesmo que não lhe era própria e que tinha a função de manter a dominação europeia. Essa interiorização da consciência do 'outro' dentro de si mesmo é que determinava o caráter espúrio das culturas nascentes, impregnadas em todas as suas dimensões de valores exógenos e desenraizadores. [...] os povos coloniais [...] eram também degradados ao assumirem como autoimagem um reflexo da visão europeia que os descrevia como racialmente inferiores, porque negros, indígenas ou mestiços, e só por isso condenados ao atraso, como fatalidade decorrente de suas características inatas de preguiça, de falta de ambição, de tendência à luxúria, etc. (Darcy RIBEIRO, 2007, p. 72).

Esse processo de violência simbólica, como já comentado anteriormente através das postulações de Bourdieu (2002), é igualmente característico das relações de poder entre gêneros. Através dessas leituras, torna-se evidente que a construção de uma identidade social passa por aspectos dinâmicos e relacionais, trazendo a interseccionalidade como movimento axiomático. A noção de articulação entre as categorias, portanto, é entendida como a realização de uma correspondência entre elas, de maneira que se cria uma nova identidade fundada nos resultados dessa prática articulatória (Adriana PISCITELLI, 2008, p. 267). A partir disso, entende-se que não existem opressões isoladas no contexto comentado; a violência contra o colono perpassa a violência de gênero em uma articulação que modifica a identidade social dos sujeitos subjugados.

Diante dessas novas identidades, é considerável assinalar que, mesmo após a libertação, a tomada de consciência dos povos e as lutas engendradas, a cultura androcêntrica, do branco, do ocidental, ainda é sinônimo de cultura, ainda é universalizada. O imaginário sobrevive graças aos procedimentos imperialistas que impedem uma autêntica libertação, principalmente a nível cultural e psíquico. Darcy Ribeiro (2007, p. 39) comenta que as sociedades outrora colonizadas passam, após sua suposta libertação, por um processo de atualização histórica ${ }^{3}$ que só tem como resultado a ascensão da condição de colônia escravista de metrópoles bem determinadas à condição de áreas de exploração neocolonial subservientes ao imperialismo industrial. Essa realidade mantém as práticas de exclusão e desigualdade muito porque conserva o inconsciente coletivo criado desde o primeiro momento de exploração.

Surge, então, a necessidade de redescobrir as culturas autóctones. Fanon (1968, p. 174) discute os esforços que muitos intelectuais colonizados fazem em prol de reviver e resgatar uma cultura anterior ao período colonial. Isso decorre do medo de se verem submergidos e diminuídos diante da cultura do Ocidente. Esses intelectuais, assombrados pelo perigo de perderem-se para seu povo, buscam retomar um contato com as raízes pré-coloniais de sua nação. Entretanto, não se trata somente de buscar no passado do povo elementos que possam ir contra os estereótipos e as mentiras contadas pelos colonizadores. O intelectual, para fazer com que o povo se sinta capaz, deve lutar junto a eles, dando-lhes esperança para a construção de um novo futuro. Nas palavras de Fanon (1968),

não é suficiente, portanto, mergulhar no passado do povo para encontrar aí elementos de coesão em face dos empreendimentos falsificadores e negativos do colonialismo. É necessário trabalhar, lutar no mesmo ritmo do povo a fim de determinar o futuro, preparar o terreno onde já se manifestam impulsos vigorosos (p. 194).

Assim, a tomada de consciência seguida de uma ação que visa à mudança estrutural da sociedade é que determina o potencial de reivindicação voltado para a superação do sistema racista. No entrelaçamento das opressões, a recuperação de uma cultura que traga a mulher não branca como sujeito ativo em sua comunidade é dificultosa porque se trata de um tipo que foi apagado da história da civilização em dois níveis que se relacionam entre si e que são igualmente violentos: a discriminação de gênero e a discriminação étnica. Entretanto, com o avanço dos estudos feministas e pós-coloniais, atualmente não só os trabalhos que visam ao restabelecimento da memória desses agentes estão em crescente, mas também a sua reintegração na sociedade a partir de uma agência crítica que leva à participação e ocupação de lugares outrora negados.

\footnotetext{
${ }^{3}$ A atualização histórica é um termo cunhado por Ribeiro (2007, p. 31-32), em contraposição ao termo aceleração evolutiva. Tratam-se de dois processos civilizatórios distintos que afetam os povos de forma diversa no desenvolvimento da expansão civilizatória. A aceleração evolutiva diz respeito aos povos agentes, às sociedades que dominam a tecnologia, que progridem e preservam suas características étnico-culturais. Já a atualização histórica designa os povos passivos, subjugados por outras sociedades, descaracterizados étnico-culturalmente e que experimentam os resultados da evolução dos povos desenvolvidos de maneira imposta e arbitrária.
} 


\section{Resistência e descolonização}

Fanon (1968, p. 124) considera a dificuldade de uma nova estruturação das sociedades descolonizadas territorialmente. Criar uma nova estrutura, principalmente na esfera psicológica dos seres, é trabalhoso e, a exemplo do processo inverso, também violento. Isso porque a articulação entre raça e gênero encontra uma outra intersecção: a classe. A realidade econômica afeta de maneira brutal a identidade social das pessoas, exatamente da mesma maneira que as outras duas esferas discutidas ao longo deste trabalho.

Nos países que foram colônias, um grupo contribuiu muito para a perpetuação do sistema colonialista de exploração, mesmo após a libertação: trata-se da burguesia nacional. É sabido que a burguesia que se eleva ao poder logo ao fim do regime colonial é uma burguesia subdesenvolvida; seu poder econômico não chega aos pés do poder econômico da burguesia metropolitana, aquela a qual pretendeu substituir. É uma burguesia que não visa a investimentos produtivos, inventivos, construtivos. Ela é imediatista e serve apenas como intermediária dos negócios da grande burguesia, a real detentora do poder econômico mundial. É uma burguesia que "tem uma psicologia de homem de negócios e não de capitães de indústria" (FANON, 1968, p. 124).

Dentro dessa perspectiva, é a própria burguesia nacional, do alto da sua decadência e fomentada pelas burguesias ocidentais que criam nos países subdesenvolvidos a característica de parque de diversões. Ela organiza locais de repouso e recreação para o gozo das burguesias ocidentais, ação que aquece o turismo, um elemento que tomará conta da indústria nacional. Fanon dá o exemplo da América Latina, local onde a burguesia nacional oferece seus próprios bens e seu próprio povo para o divertimento dos europeus. As praias do Rio de Janeiro e os cassinos de Havana são citados, mas o mais problemático é quando o humano se torna um elemento turístico. E um exemplo disso são as mulheres latinas; negras, indígenas e mestiças. Essas mulheres são fetichizadas como produtos, objetos que integram a paisagem e a indústria turística. Fanon (1968) chega a comentar sobre "mestiças de treze anos" (p. 127), aludindo à exploração infantil e ao turismo sexual que ocorre nesses países. É como se as nações latino-americanas e o próprio povo tivessem sido convertidos a simples elementos de diversão para as burguesias ocidentais; tudo isso porque a burguesia nacional "não tem ideias, porque está encerrada em si mesma, separada do povo, minada por sua incapacidade congênita para pensar no conjunto dos problemas em função da totalidade da nação" (FANON, 1968, p. 128). Assim, a burguesia nacional age como se fosse gerente das empresas do Ocidente, fortalecendo as opressões.

Posto isso, faz-se necessária uma descolonização complexa que perpassa todas as esferas. Uma opção de práxis que afetaria as estruturas dessas sociedades discutidas ao longo do trabalho seria o que Lugones (2014, p. 939) chama de descolonização de gênero. Para ela, descolonizar o gênero "é decretar uma crítica da opressão de gênero racializada, colonial e capitalista heterossexualizada visando [a] uma transformação vivida do social” (LUGONES, 2014, p. 940). Essa crítica se dá por meio de uma compreensão histórica que evidencia as relações de opressão e resistência, atribuindo agência às categorias humanas consideradas apenas passivas ao longo dos tempos. Não se trata, nesse caso, de levar informações às mulheres permitindo com que elas simplesmente compreendam sua situação, mas também de não deixar com que elas se submetam mais a essa conjuntura. Por isso, o feminismo descolonial deve atuar no sentido de descolonizar até mesmo o conhecimento gerado nesses contextos, posto que há uma violência epistemológica notável. Dentro do próprio movimento feminista emergente de países colonizados pode existir, a partir do lugar de privilégio de classe, raça e sexualidade de suas representantes majoritárias, uma reprodução do discurso colonialista que ignora cada experiência vivida por mulheres em diferentes e específicos cenários, especialmente as experiências vividas por negras, indígenas e mestiças (Yuderkys Espinosa MIÑOSO, 2009, p. 45). A descolonização do feminismo, portanto, deve exercer uma articulação das lutas anticapitalista, antipatriarcal e antirracista. Novamente, trata-se de uma tática de ação que vai muito além do reconhecimento elementar da situação de opressão.

Esse mesmo procedimento é adotado por Fanon. Sartre (In FANON, 1968, p. 8) aponta que o filósofo martiniquense procura exatamente explicar e desmontar os mecanismos de alienação a seus irmãos negros, e, pela relação, explica a alienação dos próprios brancos. Ao longo de Os Condenados da Terra, de Pele Negra, Máscaras Brancas, e de outros textos, o que se nota é a chamada à tomada de consciência e à agencialidade; o autor não apenas descortina a realidade, mas também aponta possibilidades de movimento.

Para que seja propelido no oprimido o sentimento de luta visando a mudanças estruturais, é necessário que se traga ao conhecimento as figuras que representaram resistência nos contextos e situações de subjugação, em um movimento contrário feito pelos esforços colonialistas. Ao propor a descolonização de gênero, Lugones (2014) comenta a necessidade de compreender a resistência mascarada pela teia colonial:

A colonialidade do gênero permite-me compreender a opressão como uma interação complexa de sistemas econômicos, racializantes e engendrados, na qual cada pessoa no 
encontro colonial pode ser vista como um ser vivo, histórico, plenamente caracterizado. Como tal, quero compreender aquele/a que resiste como oprimido/a pela construção colonizadora do lócus fraturado. Mas a colonialidade do gênero esconde aquele/a que resiste como um/ uma nativo/a, plenamente informado/a, de comunidades que sofrem ataques cataclísmicos. Assim, a colonialidade do gênero é só um ingrediente ativo na história de quem resiste. Ao enfocar naquele/a que resiste situado/a na diferença colonial, minha intenção é revelar o que se torna eclipsado (p. 942).

Porém, essa resistência não é individual, nem necessariamente intelectualizada. É vivida a partir da percepção do estado de outras pessoas comuns, que passam pelos mesmos problemas e que permitem a identificação, criando novas condições de possibilidade, agora em prol de uma luta partilhada. Logo, entende-se que uma maneira comunitária de se organizar é exatamente o que pode persistir como oposição à colonialidade. Esse sentimento de comunidade também é tratado por Fanon como elemento base para um movimento de libertação total, mas que só acontece quando o indivíduo colonizado reorganiza as categorias do humano em sua esfera psíquica. $O$ autor lembra, nesse ponto, que não é suficiente que se lute apenas pela liberdade de um povo. É necessário, em todo o tempo em que dure o combate, reensinar ao povo e a si mesmo a dimensão do ser humano. Ele diz que "é preciso percorrer os caminhos da história do homem condenado pelos homens e provocar, tornar possível, o encontro de seu povo e dos outros homens" (FANON, 1968, p. 253). Isso tudo porque o colonialismo despersonalizou o sujeito colonizado e essa despersonalização é sentida inclusive coletivamente, afetando as estruturas sociais. É como se o povo colonizado passasse a somente encontrar fundamento na existência quando na presença dos colonizadores; torna-se uma relação de dependência, por mais estranho e violento que possa parecer.

\section{Conclusão}

O artigo pretendeu expor as considerações feitas por Frantz Fanon sobre o colonialismo relacionando-as às teorias feministas que procuram analisar a condição das mulheres não brancas nos contextos de países que foram colonizados. Foi discutido como a mentalidade discriminatória e repressora dos colonizadores penetrou as ordens psíquicas e culturais dos povos subjugados e também como a descolonização do pensamento e da cultura pode ser empreendida a fim de atingir uma mudança estrutural.

A utilização do método de análise interseccional foi feita de modo que fosse possível mostrar que gênero, raça e classe não são esferas isoladas e diferentes da experiência humana (PISCITELLI, 2008, p. 268). São categorias que coexistem, que se entrelaçam e formam a identidade ativa dos sujeitos, estando aqui em destaque os sujeitos pertencentes a espaços colonizados. Justamente por conta dessas relações é que essas categorias são articuladas, o que trouxe relevância e coerência ao longo da discussão proposta.

Através de suas obras, Fanon pretendeu suscitar a tomada de consciência do complexo de inferioridade do negro, do colonizado, a fim de que nele nasça um potencial de reivindicação voltado para a superação do sistema colonial e racista. Atrelando a situação feminina nesse contexto, este estudo também pretendeu suscitar, de modo relacional, a agencialidade da mulher não branca, retirada do centro das discussões várias vezes pelo prevalecimento da cultura hegemônica. É imprescindível que se recuse a universalização do masculino, ou do ocidental, ou do branco, a partir da valorização da diferença. Essa ação evita uma aceitação acrítica de um aglomerado de valores que se encontra amplamente vinculado às relações de dominação.

Por fim, é inevitável recorrer à Judith BUTLER (2012, p. 206-207) quando comenta as tantas intersecções que compõem a vida de um indivíduo. A teórica aponta a incompletude que essas posições de adjetivos oferecem, mas entende que é uma incompletude instrutiva. Para ela, existe um esgotamento que é comum a todos os processos ilimitáveis de significação; as categorias não cessam, são múltiplas e impossíveis de serem apreendidas em suas totalidades. Entretanto, no final das contas, esse inapreensível se mostra como um novo ponto de partida para as discussões e teorizações feministas.

\section{Referências}

BEAUVOIR, Simone de. O segundo sexo. Tradução de Sérgio Milliet. Rio de Janeiro: Nova Fronteira, 2009.

BONNICl, Thomas. "Teoria e crítica pós-colonialistas". In: BONNICl, Thomas; ZOLIN, Lúcia Osana (Org.). Teoria literária: abordagens históricas e tendências contemporâneas. 3. ed. Maringá: EDUEM, 2009. p. 257-285.

BOURDIEU, Pierre. A dominação masculina. Tradução de Maria Helena Kühner. 11 .ed. Rio de Janeiro: Bertrand Brasil, 2002. 
BRAH, Avtar; PHOENIX, Ann. "Ain'† I A Woman? Revisiting intersectionality". Journal of International Women's Studies, v. 5, n. 3, p. 75-86, maio 2004.

BUTLER, Judith. Problemas de gênero: feminismo e subversão da identidade. Tradução de Renato Aguiar. 4.ed. Rio de Janeiro: Civilização Brasileira, 2012.

CAPÉCIA, Mayotte. Je suis Martiniquaise. Paris: Córrea, 1948.

CORREAL, Diana Marcela Gómez. "Feminismo y modernidad/colonialidad: entre retos de mundos posibles y otras palabras". En otras palabras..., Bogotá, n. 12, p. 43-61, 2011.

CURIEL, Ochy. "Hacia la construcción de un feminismo descolonizado". In: MIÑOsO, Yuderkys Espinosa (Coord.). Aproximaciones críticas a las prácticas teórico-políticas del feminismo latinoamericano. Buenos Aires: En la Frontera, 2010.

DAVIS, Angela. Mulher, raça e classe. Tradução livre. Lisboa: Plataforma Gueto, 2013.

FANON, Frantz. "Argelia se quita el velo". In: FANON, Frantz. Sociología de una revolución. Traducción de Víctor Flores Olea. 3.ed. Ciudad de México: Ediciones Era, 1976. p. 19-45.

FANON, Frantz. Os condenados da terra. Tradução de José Laurênio de Melo. Rio de Janeiro: Civilização Brasileira S.A., 1968.

FANON, Frantz. Pele negra, máscaras brancas. Tradução de Renato da Silveira. Salvador: EDUFBA, 2008.

FANON, Frantz. "Racismo e cultura". In: FANON, Frantz. Em defesa da revolução africana. Tradução de Isabel Pascoal. Lisboa: Livraria Sá da Costa, 1980. p. 34-48.

GORDON, Lewis R. What Fanon Said: A Philosophical Introduction to His Life and Thought. New York: Fordham University Press, 2015.

LACAN, Jacques. O seminário - livro 5: as formações do inconsciente. Tradução de Vera Ribeiro. Rio de Janeiro: Jorge Zahar, 1999.

LUGONES, Maria. "Rumo a um feminismo descolonial". Tradução de Juliana Watson e Tatiana Nascimento. Revista Estudos Feministas, Florianópolis, v. 22, n. 3, p. 935-952, set./dez. 2014.

MARCUSE, Herbert. Ideias sobre uma teoria crítica da sociedade. Tradução de Fausto Guimarães. Rio de Janeiro: Zahar, 1972.

MIGUEL, Luis Felipe. "A identidade e a diferença”. In: BIROLI, Flávia; MIGUEL, Luis Felipe. Feminismo e política: uma introdução. São Paulo: Boitempo, 2004. p. 57-65.

MIÑOSO, Yuderkys Espinosa. "Ełnocentrismo y colonialidad en los feminismos latinoamericanos: complicidades y consolidación de las hegemonías feministas en el espacio transnacional". Revista Venezolana de Estudios de la Mujer, Caracas, v. 14, n. 33, p. 37-54, jul./dez. 2009.

OLIVEIRA, Vanilda Maria de. Um olhar interseccional sobre feminismos, negritudes, lesbianidades em Goiás. 2006. Dissertação (Mestrado em Sociologia) - Universidade Federal de Goiás, Goiânia, Goiás, Brasil.

PISCITELLI, Adriana. "Interseccionalidades, categorias de articulação e experiências de migrantes brasileiras". Sociedade e Cultura, Goiânia, v. 11, n. 2, p. 263- 274, jul/dez 2008.

RIBEIRO, Darcy. As Américas e a civilização: processo de formação e causas do desenvolvimento desigual dos povos americanos. São Paulo: Companhia das Letras, 2007.

SAPEDE, Thiago C. "Racismo e Dominação Psíquica em Frantz Fanon". Sankofa - Revista de História da África e de Estudos da Diáspora Africana, São Paulo, v. 4, n. 8, p. 44-52, dez. 2011.

SARTRE, Jean-Paul. "Prefácio". In: FANON, Frantz. Os condenados da terra. Tradução de José Laurênio de Melo. Rio de Janeiro: Civilização Brasileira S.A., 1968. p. 3-21.

SPIVAK, Gayatri Chakravorty. Pode o subalterno falar? Tradução de Sandra Regina Goulart Almeida, Marcos Pereira Feitosa e André Pereira Feitosa. Belo Horizonte: EDUFMG, 2010.

TODOROV, Tzvetan. A conquista da América: a questão do Outro. Tradução de Beatriz PerroneMoisés. São Paulo: Martins Fontes, 1983. 
Jéssica Antunes Ferrara (j.antunesferrara@gmail.com) é doutoranda em Estudos Literários - Literatura, Crítica e Cultura - pela Universidade Federal de Juiz de Fora. Mestre em Estudos Literários - Literatura, Identidade e outras manifestações culturais pela Universidade Federal de Juiz de Fora (2019). Graduada em Letras pela Universidade Federal de Juiz de Fora (2016), com ênfase em Literatura em Língua Portuguesa. Desenvolve pesquisa com foco em Literatura Comparada, Crítica Social e Estudos de Gênero na América Latina.

\section{COMO CITAR ESSE ARTIGO DE ACORDO COM AS NORMAS DA REVISTA}

FERRARA, Jéssica Antunes. "Diálogos entre Colonialidade e Gênero". Revista Estudos Feministas, Florianópolis, v. 27, n. 2, e54394, 2019.

\section{CONTRIBUIÇÃO DE AUTORIA}

Concepção, coleta de dados e análise de dados, elaboração do manuscrito, redação e discussão de resultados.

\section{FINANCIAMENTO}

Não se aplica

\section{CONSENTIMENTO DE USO DE IMAGEM}

Não se aplica

APROVAÇÃO DE COMITÊ DE ÉTICA EM PESQUISA

Não se aplica

\section{CONFLITO DE INTERESSES}

Não se aplica

\section{LICENÇA DE USO}

Este artigo está licenciado sob a Licença Creative Commons CC-BY Internacional. Com essa licença você pode compartilhar, adaptar, criar para qualquer fim, desde que atribua a autoria da obra.

\section{HISTÓRICO}

Recebido em 04/12/2017

Reapresentado em 18/09/2018

Aprovado em 19/09/2018

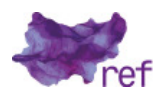

